\title{
NUMERICAL STUDIES ON FLAT SLAB STRCTURES SUPPORTED ON NON-RECTANGULAR GRIDS
}

\author{
Jayaprakash Narayana. $\mathbf{S}^{\mathbf{1}}$, Sreenivas Sarma. $\mathbf{P}^{\mathbf{2}}$ \\ ${ }^{1}$ Assistant Professor, Department of Civil Engineering ,Mahatma Gandhi Institute of Technology,Telangana, India \\ ${ }^{2}$ Professor \& Head, Department of Civil Engineering, Chaitanya Bharathi Institute of Technology, Telangana, India
}

\begin{abstract}
Construction of flat slab structures has increased enormously in recent times. Well established procedures are available in the literature and codes for the analysis, design and detailing of flat slab structures supported on regular rectangular column grids. However, these structures pose a greater challenge to the designers, when they are supported on non-rectangular column grids. Use of non- rectangular column grids is often necessitated in the modern context, due to varied parking requirements, floor wise variation of building plans, site constraints etc.

Besides, the seismic performance of flat slab structures has been the subject of interest for the researchers over the years. Though their works established the behavior of flat slabs supported on regular rectangular grids to a greater extent, the seismic behavior of flat slab structure supported on non-rectangular grids, still needs detailed investigations. Lack of adequate information in literature and non availability of standard specifications in codes on these types \& structures indicate the immediate necessity for such investigations.
\end{abstract}

This paper presents the inferences of extensive numerical investigations on a chosen flat slab structure for possible shifting, breaking and new formations of column strips with the variation in the position of an interior column, which makes the regular rectangular grids into non- rectangular. The sensitivity of the structure is explored by varying the position of an interior column. The variation of moments and shears in column strips in the flat slab under static and dynamic loads are observed and are also plotted. Further, a 10 storeyed flat slab structure is analysed and the results are studied to know the effect of staggering a column of a rectangular grid, on the moments in chosen (corner, side and interior) columns, under both static and dynamic loads. Results reveal that there is every need to consider the effect of non rectangularity column grids on the formation of column strips, moments and shears in column strips, the detailing of reinforcement in column strips and also the moments in the columns of such flat slab structures.

Keywords: Flat slab structures, Non- rectangular grids, shifting of column strips, seismic performance

\section{INTRODUCTION}

In the recent times, Hyderabad has became a hub for infra structural activity. Many multi-storeyed buildings for official and commercial purposes have come in the last couple of years. Understandably, most of these have used Flat slab concept, due to their well known advantages. The city was having only few flat slab constructions during late 1980's. One building belonging to BSNL in Nampally, one of the Municipality parking complex at Abids, one for the proposed stock market in Errum Manzil were among those countable few. This number has now grown into hundreds of such types, in and around the twin cities of Hyderabad and Secunderabad. It is therefore imperative that the structural engineers in this part of the world have a responsibility of understanding their behavior properly and contributing for the effective implementation of appropriate concepts.

Lack of understanding of the behavior of Flat slabs in respect of the following aspects, leads too many problems in the construction of such slabs. Some of the commonly identified problems are (a) Local behavior of slabs surrounding the internal columns with respect to moment and shear transfer from the slab to the column

(b) Local behavior of edge and corner columns at their intersections with the slab

(c) Effects of punching shear and modifications due to presence of drops, columns capitals and inevitable openings

(d) Overall design and detailing

Besides these problems, the very definitions of column strips and middle strips are given only for regular rectangular grids in literature. For the cases of staggered column grids, these very definitions remain questionable. In modern multi-storeyed complexes irregular column grids with staggered column locations are very common due to varied parking requirements, floor wise variation of building plans, site constraints etc. In this context there is every need to conduct extensive studies on such structures for the proper understanding of their behavior. 


\section{METHODOLOGY ADOPTED}

In this work extensive numerical studies are conducted on Flat slab structures to determine the effect of staggering a column with respect to its original location in a regular grid, in both directions. For each of these staggered locations, the response of the structure in terms of strip moments and punching shears is observed under static as well as seismic loadings and is compared with that in regular grids. An attempt is made to identify the possible shifting and /or reformations of column strips and middle strips and suggest suitable reinforcement patterns that could well act as ready reckoners for practitioners. Further, a 10 storeyed flat slab structure is analysed and the results are studied to know the effect of staggering a column of rectangular grid, on the moments in chosen (corner, side and interior) columns, under both static and dynamic loads. Structural Engineering softwares viz. ETABS and SAFE were used for the finite element analysis of flat slabs.

\section{NUMERICAL STUDIES}

A number of numerical models were analyzed as a part of the study. Broadly, the studies were made in two phases. In the first phase, the effect $t$ of staggering an interior column on the moments and shears in the column strips is investigated. The very formation and/or de-linking of column strips are also explored in this phase. In the second phase, the effect of staggering an interior column on the moments is chosen columns (viz. corners, side and interior columns) is studied. For this purpose, a ten storeyed building was considered the details are given here under.

\subsection{Phase-I Study:}

In the regular grid considered for the study, the position of column C-3 is varied each time with respect to its original position. i.e. co-ordinates $(\mathrm{x}, \mathrm{y})$ are varied from 0 to $3 \mathrm{~m}$, in both $\mathrm{X}$ and $\mathrm{Y}$ directions. The variation in moments in the column strips connecting the inner and outer peripheral columns as well as the punching shears are noted simultaneously, the possibility of formation of new column strips and breaking/de-linking of the existing column strips (of the regular grid) is also explored. Typical models created for phase -I study are given in fig. 1 .

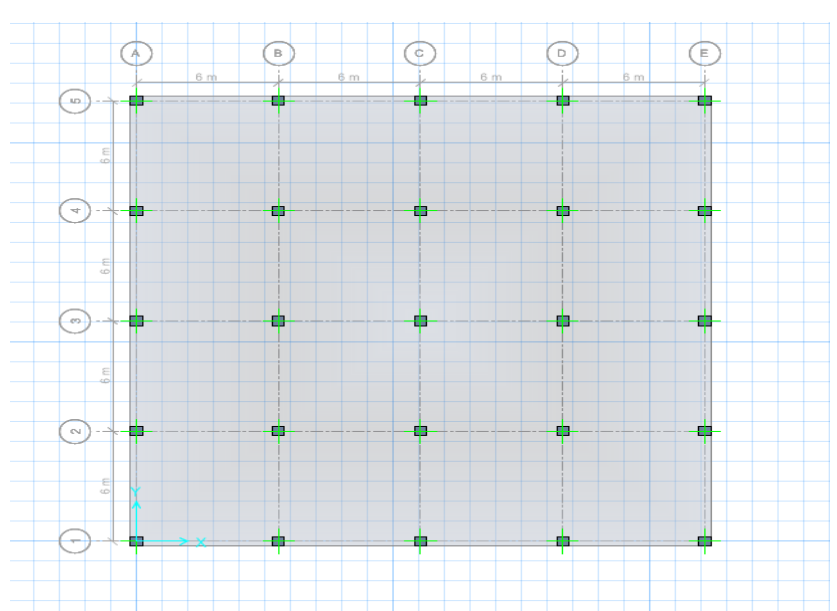

\subsection{Phase-II Study:}

A ten storeyed building having the same column grid as shown in fig 1 is analyzed for static as well as earthquake loading (zone-II) using response spectrum approach. Variation of moments, shears in chosen columns, i.e. 'Corner', 'Side' and 'interior' columns is observed for the load combinations 1.5(DL+LL) (combination 2), 1.2(DL+LL-EQX) (combination 6) and 1.2(DL+LL-EQY) by varying the positions $\mathrm{P}(\mathrm{x}, \mathrm{y})$ of the central column, with respect to its original location $(0,0)$. ' $x$ ' and ' $y$ ' are varied from $0 \mathrm{~m}$ to $3 \mathrm{~m}$, spells of $1 \mathrm{~m}$.

For each variation in the position of the interior column C-3, the variation in the moments and shears in the three (corner, side and interior) columns are observed in all floors and the critical values in each of the three are noted. This exercise is repeated for both static and seismic loadings. The purpose of this exercise is mainly to note the effect on the columns in a flat slab structure, as the flat slab structure, as the flat slabs themselves are generally know for underperforming when compared to a beam-slab structure. This aspect is carefully examined in this exercise apart from noting the variation of moments and shears in a floor slab and bringing a comparison between the study in phase-I and that in phaseII.

\subsection{Structural Models}

For phase-I study all the structural models were created and analysed in 'SAFE'. However, the seismic analysis was performed in ETABS and the results were exported to 'SAFE' as the slab design is very convenient in 'SAFE', when compared to 'ETABS'. Some typical models created in 'SAFE' and 'ETABS' for phase-I study are presented here.

For phase-II study all the structural models for the chosen 10 storeyed buildings were created and analysed in ETABS and only the results of a typical floor were exported to 'SAFE', for bringing out a comparative study between phase-I study and phase-II study. Few typical structural models created in ETABS and SAFE, for phase - II study are presented here.

\section{RESULTS AND DISCUSSIONS}

The studies conducted on a number of numerical models in two phases, resulted in a voluminous output. These results were carefully studied and the important observations made are summerised. Attempt is made to first understand the very formation of column strips in the context of flat slabs supported on non-rectangular column grids. Further, the variation of moments and shears in slabs and columns, with the variation of position of an interior column is discussed in detail, in two phases.

Fig -1: Sample slab layout 


\subsection{Formation of Column Strips and Panels:}

\subsubsection{Static Loading}

As mentioned earlier, the position $\mathrm{P}(\mathrm{x}, \mathrm{y})$ of only one column (C-3, the central column) is varied in order to assess the sensitivity of each model to this variation, to quantify these aspects and record certain trends with ease . By definition, column strips in flat slabs replace the beams of the beam slab systems, behave like continuous beams with, of course, less rigidity. They are characterized by heavy moment concentrations in them, in relation to other parts of these slabs.

The studies conducted revealed that as the column C-3 is moving farther from its original position, the strips A3-B3 and C5-C4 are finally de-linking when ' $\mathrm{x}$ ' and/or ' $y$ ' are reaching their maximum values (i.e. for $\mathrm{P}(3,3)$ ). At this juncture the column C-3's new position(C-3') is facilitating the formation of new column strips joining C2-C3'-D3 and another C3'-D2. As is evident from fig 2, this formation is due to the proximity of columns C4,C3 and D2 with C3'. Simultaneously, heavy cantilever action is developed at the columns B3 and C4, in continuation of strips A3-B3 and $\mathrm{C} 5-\mathrm{C} 4$.

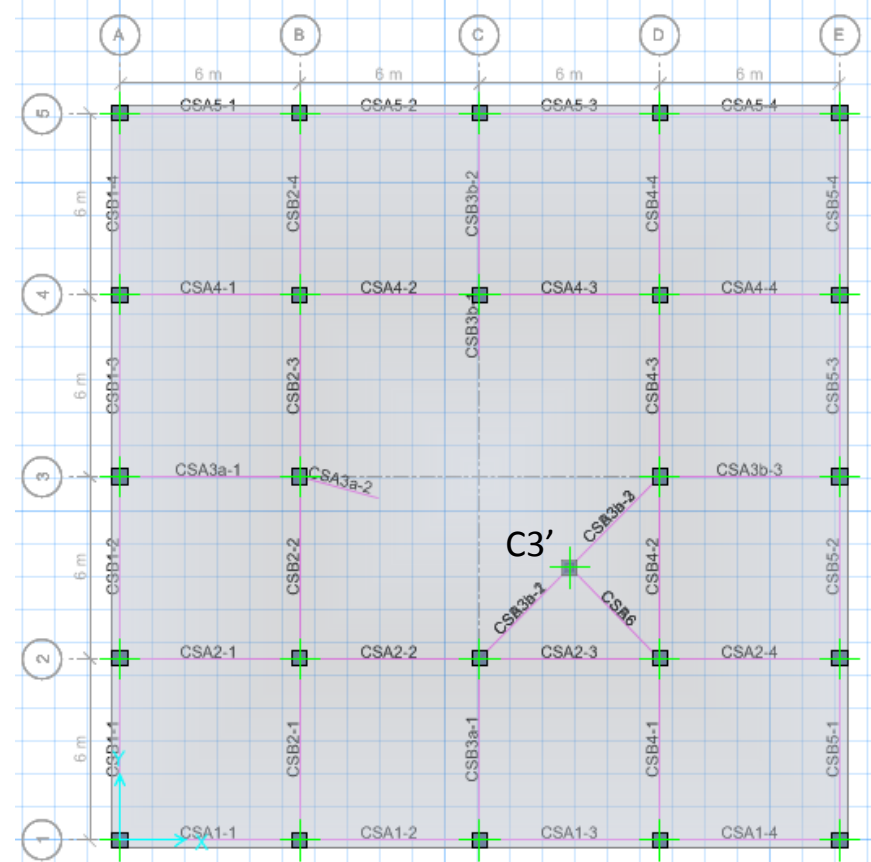

Fig -2: Formation of column strip

A an interior (central) column of a regular grid is moving away from the two adjacent columns in its vicinity, that are in orthogonally perpendicular directions to its original position, the column strips connecting this central column under consideration are breaking, when the column has moved to a position $\mathrm{P}(\mathrm{x}, \mathrm{y})$ such that $(\mathrm{x}+\mathrm{y}) \geq \mathrm{l} / 3$ where ' $\mathrm{l}$ ' is the bay length of the regular column grid chosen.

When the column is placed at a position $\mathrm{P}(\mathrm{x}, \mathrm{y})$ with respect to its original position, such that $\mathrm{x}$ and $\mathrm{y}$ are 0.51 , then a largest interior panel having an area equal to 3.5 times the original panel area is formed. Simultaneously two small panels having area equal to 0.25 times the original panel area are also formed.

It is very important to note these formations of column strips and panels and give a proper reinforcement and detailing, particularly in the diagonal column strips. The author has conducted a field study for noting the practice of reinforcement detailing in such flat slabs with nonrectangular column grids. Field study clearly reveals (fig.4) that there is a difference in what should be the actual practice (fig.3) and what is practiced in the field, regarding the reinforcement detailing.

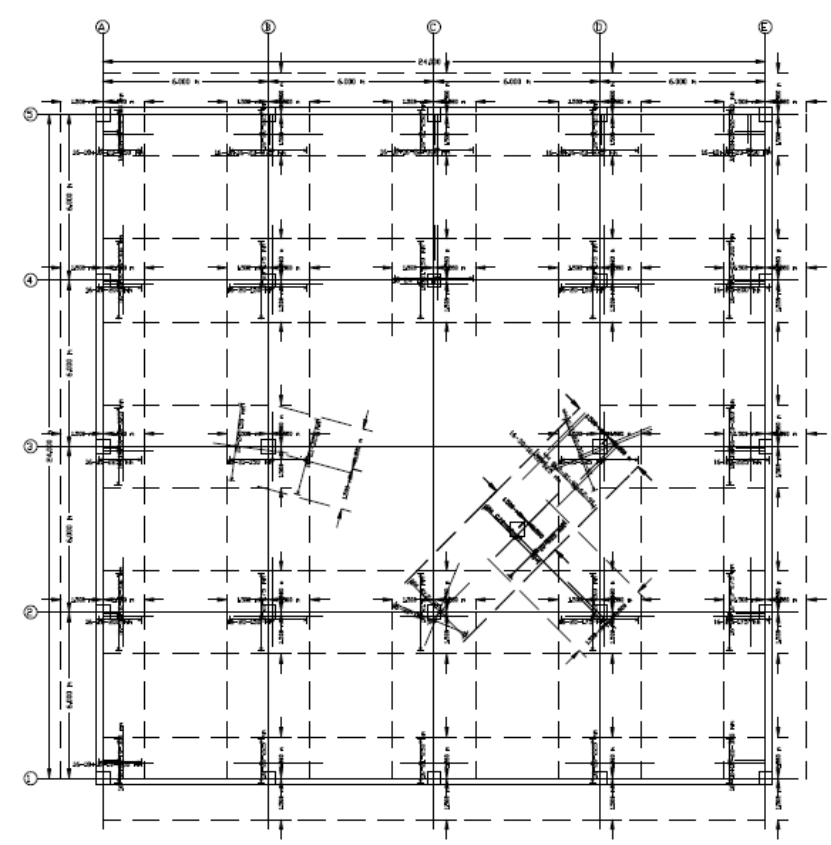

Fig -3: Top reinforcement in a flat slab with irregular column layout from 'SAFE'

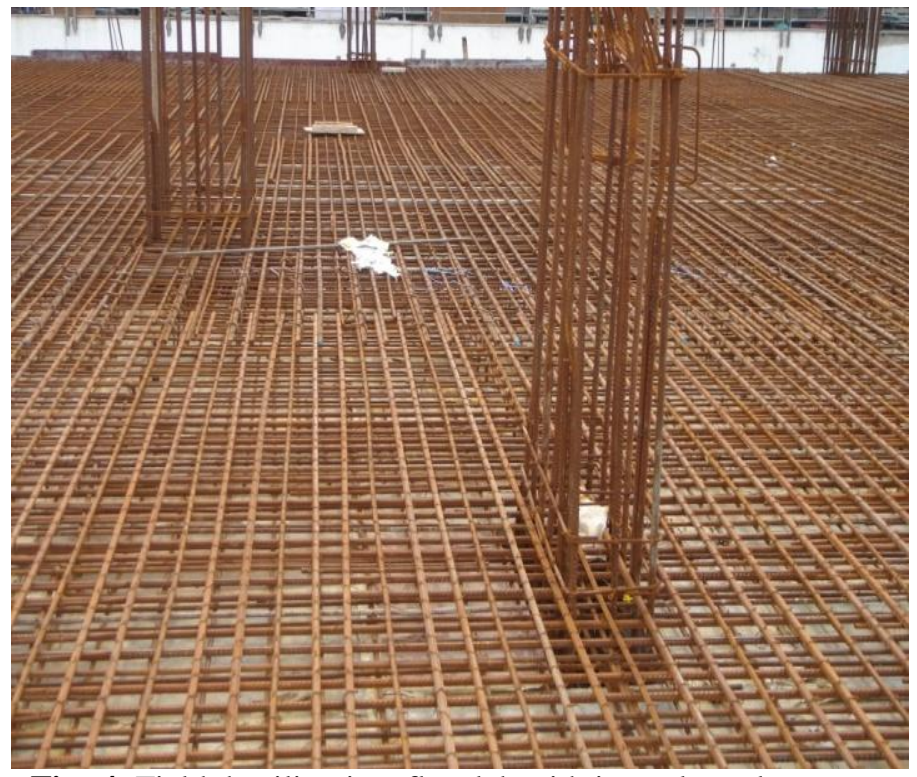

Fig -4: Field detailing in a flat slab with irregular column layout 


\subsubsection{Seismic Loading:}

As seismic analysis is not possible in 'SAFE' directly, so, the analysis is conducted in ETABS and exported to 'SAFE', for noting the column strips and panels formation. It is noted that similar trends prevail for seismic loading as of those for static loading.

\subsection{Moments and Shears in Column Strips (Phase- I}

\section{Study):}

In the study conducted in phase-I, only the flat slab is modeled without any reference to number of floors. Moments and shears in column strips are obtained by conducting both static and seismic analysis. By varying the position of the interior (central) column, the variation in the moments and shears is noted.
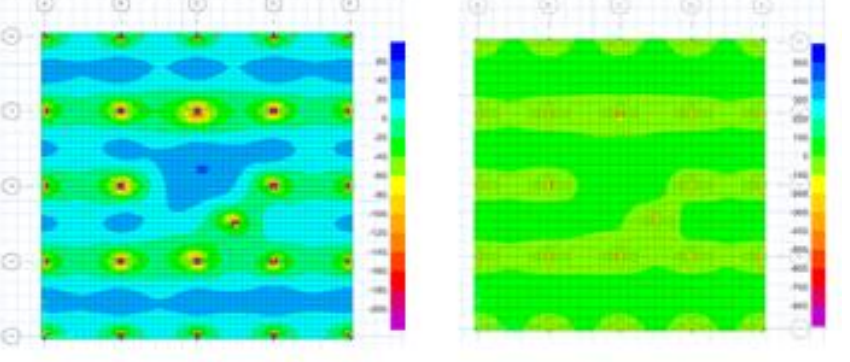

i) Honizontal strips

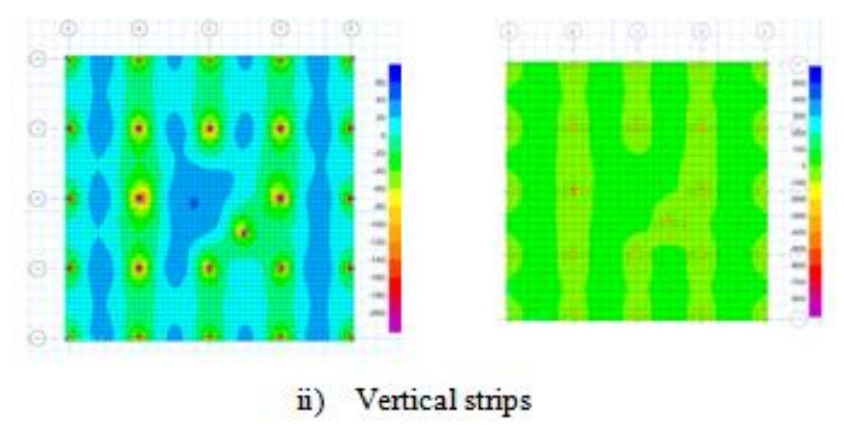
(a) Static Loading
(b) Seismic Loading

Fig -5 A typical column strips formation for Column C3's position $\mathrm{P}(3,3)$

\subsubsection{Static Loading}

\subsubsection{Moments}

Absolute maximum moments in the outer peripheral column strips occurred in the corner strips connecting D1-E1 and E1-E2, around the column D1 and E2 (fig 1.). The magnitude of this moment is $93.512 \mathrm{kN}-\mathrm{m}$ (occurring for $\mathrm{P}$ $(3,3)$ case), which is comparable with that $(91.477 \mathrm{kN}-\mathrm{m})$ occurring around column B1,D1,B5 \&D5. Absolute minimum moments $(34.201 \mathrm{kN}-\mathrm{m})$ occurred in the mid spans of strips B5-C5 and E5-D5, when the column C3 is moved by a minimum $(0,1)$ along $\mathrm{Y}$-axis. Again these are comparable with the values of $37.555 \mathrm{kN}$-m that occurred for $(0,0)$ case and occurring at the similar locations, that all round the outer periphery.
Absolute maximum moment in the inner peripheral columns occurs in A3-B3 strip and C5-C4 strip and they are in the at end span of A3-B3 and at cantilever support face of C4 respectively. The magnitude of this moment is $305.198 \mathrm{kN}$ $\mathrm{m}$ (occurring for $\mathrm{P}(3,3)$ case), which is $23 \%$ more than that (233.7 $\mathrm{kN}-\mathrm{m})$ occurring around column B3,D3,C2,B2,D2,B4\&D4. Absolute minimum bending moment $75.11 \mathrm{kN}-\mathrm{m}$ occurred in $\mathrm{C} 1-\mathrm{C} 2$ strip and D3-E3 at the cantilever faces of $\mathrm{C} 2$ and $\mathrm{D} 3$ respectively. The magnitude of this moment is $75.11 \mathrm{kN}-\mathrm{m}$ (occurring for $\mathrm{P}$ $(1,3)$ case $)$, which is $57 \%$ less than that $(118.5 \mathrm{kN}-\mathrm{m})$ occurring around column B3, C4, B2, D2, B4\&D4.

The variation of maximum moments along the column strips connecting A3-B3-C3-D3-E3 and peripheral strips along $\mathrm{X}$ direction and $\mathrm{C} 1-\mathrm{C} 2-\mathrm{C} 3-\mathrm{C} 4-\mathrm{C} 5$ and peripheral strips along Y-direction for various column position $\mathrm{P}(0,0)$ to $\mathrm{P}(3,3)$ are plotted in graphs as shown in fig 6 .
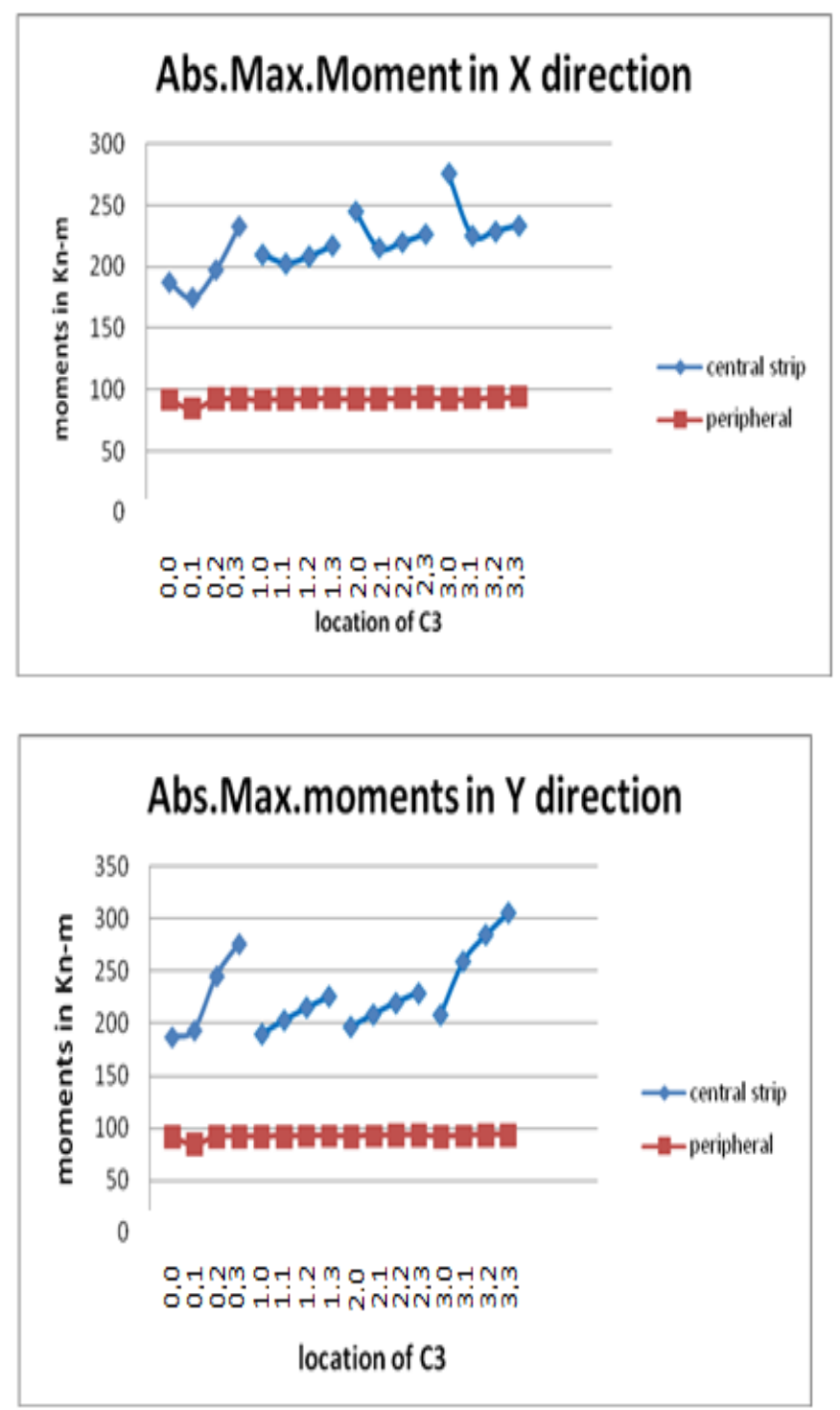

Fig 6 : Variation of Maximum moments in $\mathrm{X}$ - and $\mathrm{Y}$ directions in A3-B3-D3-E3-F3 and C1-C2-C3-C4-C5 and peripheral strips 


\subsubsection{Shears}

Absolute maximum shear occurred in both directions, in the edge strips at D1 and E1. The magnitude of this shear force is $117.292 \mathrm{kN}$ (occurring for $\mathrm{P}(3,3)$ case), which is comparable with that $(117.047 \mathrm{kN})$ occurring around column B1, D1, B5 \&D5. Absolute minimum shear force (37.515 $\mathrm{kN})$ occurred in the mid spans of strips B5-C5 and E5-D5, when the column $\mathrm{C} 3$ is moved by a minimum $(0,1)$ along $\mathrm{Y}$ axis. Again these are comparable with the values of 37.555 that occurred for $(0,0)$ case and occurring at the similar locations, that alround the outer periphery

Absolute maximum shear force in inner peripheral column occurred in A3-B3 strip and C4-C5 strip at around the B3 and $\mathrm{C} 4$ column respectively. The magnitude of this shear force $278.2 \mathrm{kN}$ (occurring for $\mathrm{P}(3,3)$ case), which is $12 \%$ more than that $(245.6 \mathrm{kN})$ occurring around column D3, C2, B2, D2, B4 \&D4. Absolute minimum shear force in inner peripheral column occurred in C1-C2 strip. The magnitude of this shear force in $95.08 \mathrm{kN}$ (occurring for $\mathrm{P}(1,3)$ case), which is $63.5 \%$ less than that $155.46 \mathrm{kN}$ around column B3, D3, C4, B2, D2, B4 \&D4.

The variation of maximum shear force along the column strips CSA3 and peripheral strips along $X$ direction and CSB3 and peripheral strips along Y-direction for various column position $\mathrm{P}(0,0)$ to $\mathrm{P}(3,3)$ are plotted in graphs as shown in fig 7.
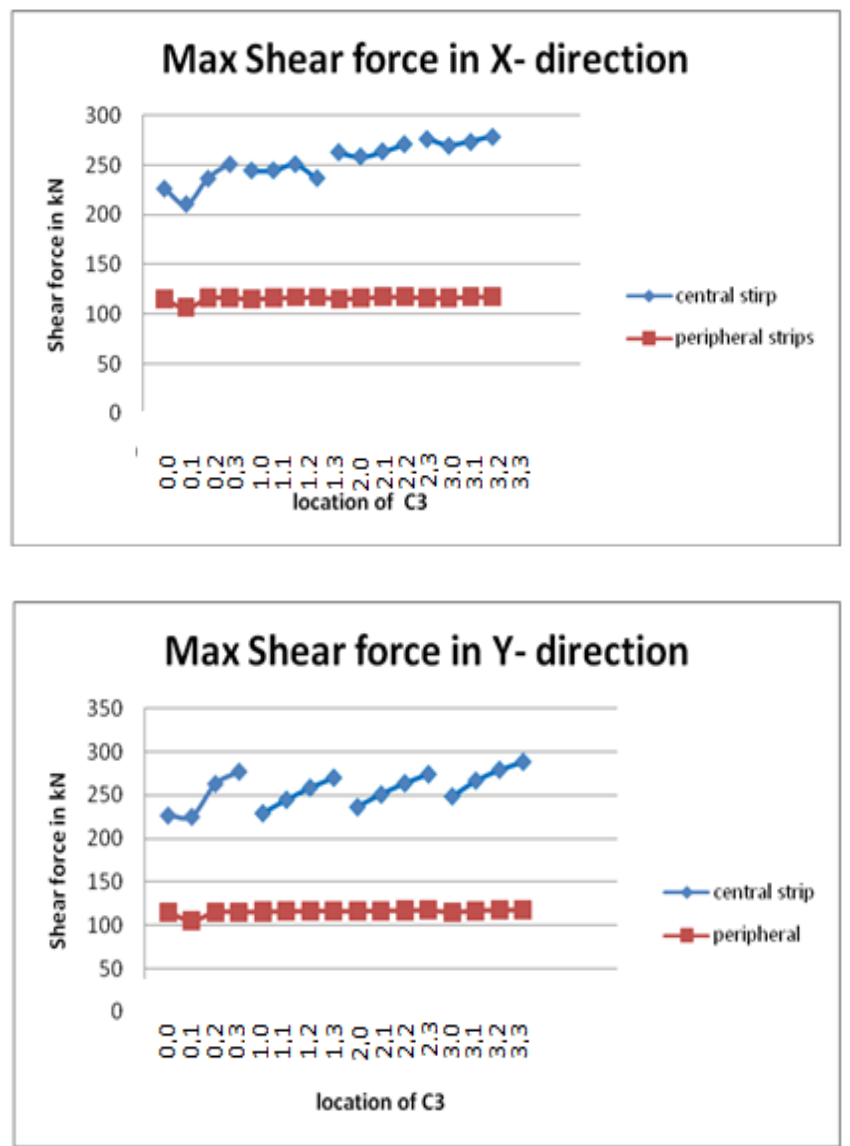

Fig 7: Variation of Maximum shear forces in $\mathrm{X}$ - and $\mathrm{Y}$ directions in A3-B3-D3-E3-F3 and C1-C2-C3-C4-C5 and peripheral strips

\subsubsection{Seismic Loading:}

\subsubsection{Moments}

Absolute maximum moments in the outer peripheral column strips occurred in the corner strips connecting D1-E1 and E1-E2, around the column D1 and E2 (fig 1). The magnitude of this moment $93.15 \mathrm{kN}-\mathrm{m}$ (occurring for $\mathrm{P}(3$, 3) case), which is $10 \%$ more than that $(84.4 \mathrm{kN}-\mathrm{m})$ occurring around B1, D1, B5 \&D5. Absolute minimum moments $(29.8 \mathrm{kN}-\mathrm{m})$ occurring in mid spans of strips B5C5 and E5-D5, when the column C3 is moved by a minimum $(0,1)$ or $(1,0)$ in both the directions, variation between the values are very minimum

Absolute maximum moments in the inner peripheral column strips occurred in the connecting A3-B3 and C5-C4 at the end of $\mathrm{A} 3 \mathrm{~B} 3$ span and at $\mathrm{C} 4$ cantilever face respectively. The magnitude of this moment $242.15 \mathrm{kN}$-m (occurring for $\mathrm{P}(3,2))$, which is $28 \%$ more than that $(173.227 \mathrm{kN}-\mathrm{m})$ occurring around D3, C4, C2, B2, D2, B4\&D4. Absolute minimum moments $(52.2 \mathrm{kN}-\mathrm{m}, 60.67 \mathrm{kN}-\mathrm{m})$ occurring in the strips E3-D3-C3' and C1-C2-C3', when C3 is moved by maximum in $\mathrm{X}$-direction and maximum in $\mathrm{Y}$-direction respectively. At D3 minimum shifting of C3 from its original position $(0,0)$ will have considerable change in magnitude of moments (for $(0,0) 131.43 \mathrm{kN}-\mathrm{m}$, for $(0,1)$ 83.17 kN-m, for $(1,0)-112.9 \mathrm{kN}-\mathrm{m})$.

The variation of maximum moments along the column strip CSA3 (i.e. A3-B3-C3-D3-E3) and peripheral strips in Xdirection and strip CSB3 (i.e. C1-C2-C3-C4-C5) and peripheral strips in $\mathrm{Y}$ - direction for all the positions of $\mathrm{C} 3$ are shown in fig 8 .
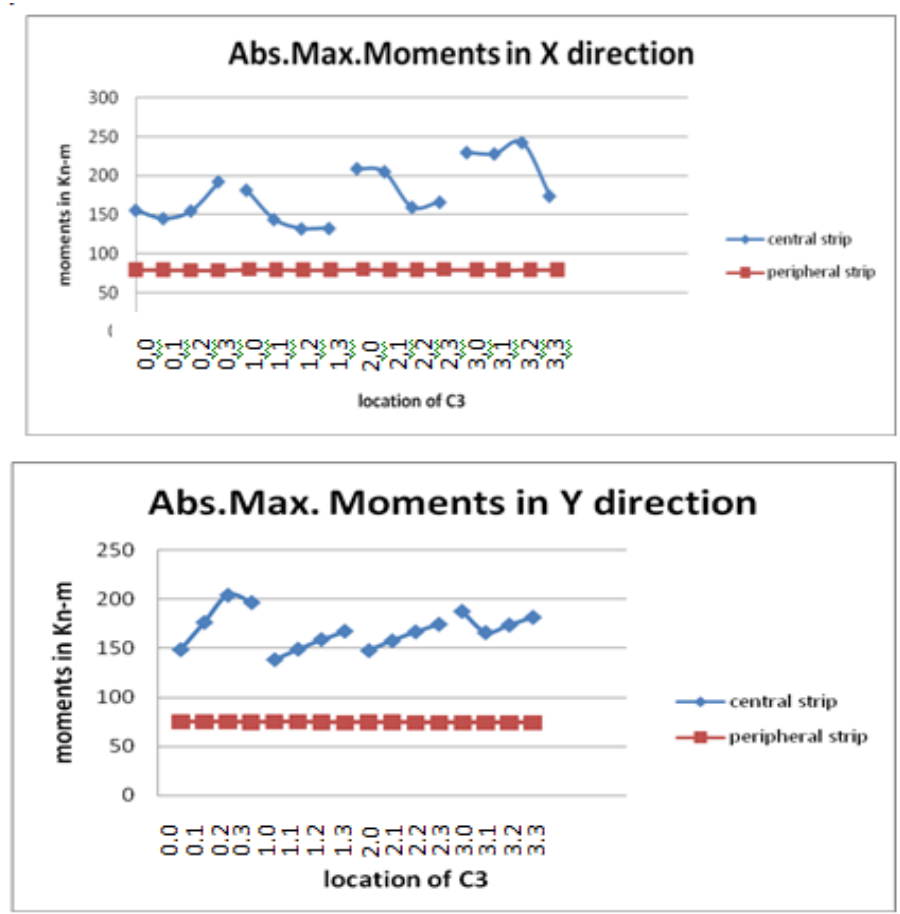

Fig 8: Variation of Maximum moments in $\mathrm{X}$ - and $\mathrm{Y}$ directions in column strips connecting A3-B3-D3-E3-F3 and C1-C2-C3-C4-C5 


\subsubsection{Shears}

Absolute maximum shear force in the outer peripheral column strips occurred in the strips connecting A1-B1-C1D1-E1 and A1-A2-A3-A4-A5, in the span of C1-D1 and A2-A3 respectively. The magnitude of this shear force is $93.78 \mathrm{kN}$ (occurring for $\mathrm{P}(1,3)$ case), which is comparable with that $(87.7 \mathrm{kN})$ occurring around B1, D1, B5 \&D5. Absolute minimum shear force $(23.02 \mathrm{kN})$ occurring in mid spans of strips C1-D1 and E3-E4.

Absolute maximum shear force in the inner peripheral column strips occurred in the strips connecting A3-B3 and C4-C5. The magnitude of this shear force is $225.75 \mathrm{kN}$ (occurring for $\mathrm{P}(1,3)$ and $\mathrm{P}(3,1)$ ), which is $13 \%$ more than that $(196.15 \mathrm{kN})$ occurring around D3, C2, B2, D2, B4 $\& D 4$. Absolute minimum shear force $(60.29 \mathrm{kN})$ occurring the in the strips of $\mathrm{C} 1-\mathrm{C} 2$ (for the case of $\mathrm{P}(1,3)$ ), which is comparable with the shear force around the other inner peripheral columns.

The variation of maximum shear force along the column strip CSA3 (i.e. A3-B3-C3-D3-E3) and peripheral strips in $\mathrm{X}$-direction and strip CSB3 (i.e. C1-C2-C3-C4-C5) and peripheral strips in $\mathrm{Y}$ - direction for all the positions of $\mathrm{C} 3$ are shown in fig 9.
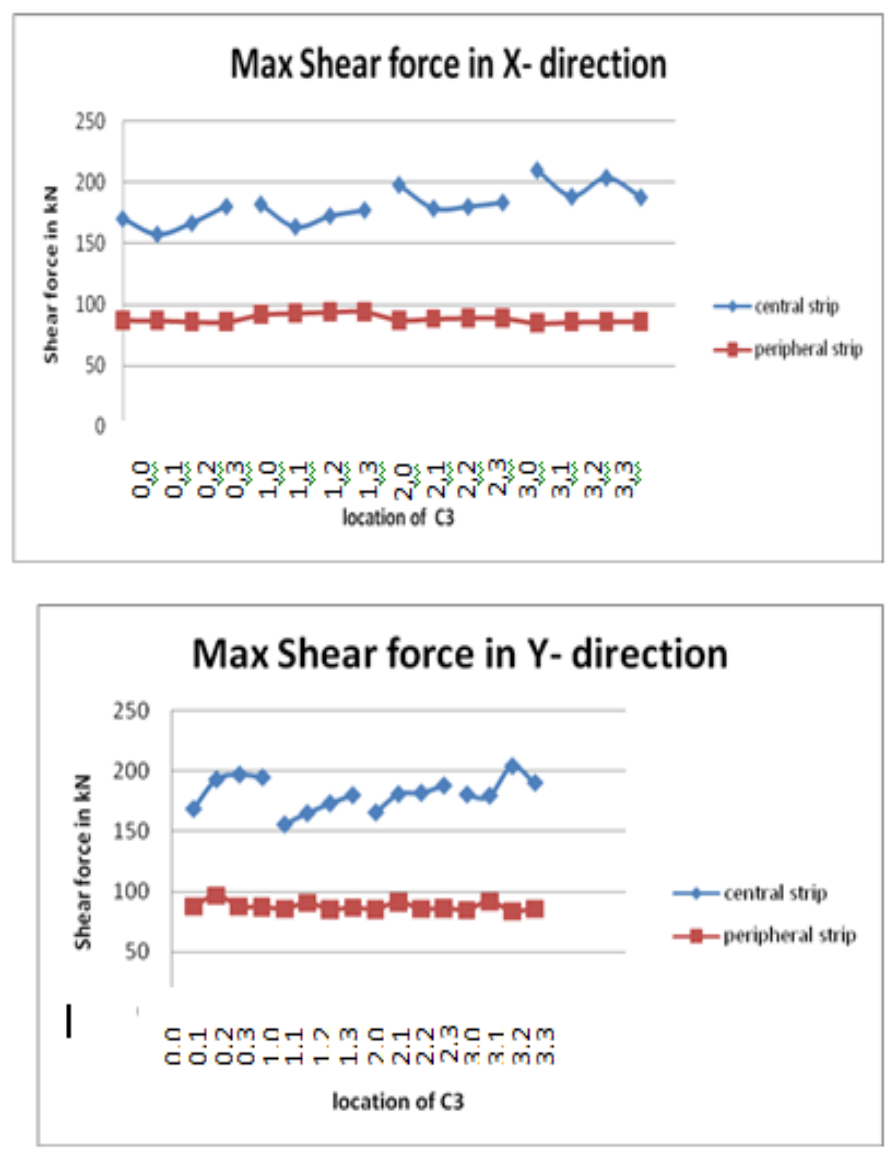

Fig 9: Variation of Maximum shear force $\mathrm{s}$ in $\mathrm{X}$ - and $\mathrm{Y}$ directions in column strips connecting A3-B3-D3-E3-F3 and C1-C2-C3-C4-C5

\subsection{Moments and Shears in Column Strips (Phase-}

II Study):

The study conducted in phase II, a 10 storey flat slab building ( 4 bays at $6 \mathrm{~m}$ in each direction) is modeled and seismic loads are applied. Columns of $650 \mathrm{~mm} \mathrm{X} 650 \mathrm{~mm}$ size and slab of $230 \mathrm{~mm}$ thickness are considered for the study. Absolute maximum moments and absolute shear forces are worked out for the typical corner columns, intermediate columns and interior columns for seismic zone II for medium soil type. The same are tabulated in Table 1, 2 and 3 .

The results indicate that the absolute maximum moments in $\mathrm{X}$ and $\mathrm{Y}$ directions are occurring for $\mathrm{P}(2,2)$ location while the absolute maximum shears in $\mathrm{X}$ and $\mathrm{Y}$ directions are occurring for $\mathrm{P}(3,3)$ and $\mathrm{P}(2,2)$ locations respectively.

Table 1- Absolute maximum moment and shear forces in a typical corner column

\begin{tabular}{|l|l|l|l|l|}
\hline & $\begin{array}{l}\text { Mx } \\
\mathrm{PN}(\mathrm{x}, \mathrm{y})\end{array}$ & $\begin{array}{l}\mathrm{My} \\
\mathrm{kN}-\mathrm{m}\end{array}$ & $\begin{array}{l}\mathrm{VN} \\
\mathrm{kN}\end{array}$ & $\mathrm{kN}$ \\
\hline 0,0 & 197.63 & 210.79 & 52.66 & 57.77 \\
\hline 0,1 & 190.54 & 198.90 & 52.10 & 60.85 \\
\hline 0,2 & 476.80 & 450.26 & 108.93 & 113.30 \\
\hline 1,0 & 477.52 & 446.30 & 110.00 & 114.95 \\
\hline 1,1 & 482.03 & 448.35 & 104.67 & 114.81 \\
\hline 1,2 & 502.73 & 468.57 & 108.83 & 119.21 \\
\hline 1,3 & 503.74 & 450.22 & 107.06 & 119.98 \\
\hline 2,0 & 508.40 & 453.61 & 107.86 & 121.00 \\
\hline 2,1 & 507.44 & 452.90 & 107.73 & 120.72 \\
\hline 2,2 & 501.49 & 468.09 & 108.50 & 118.96 \\
\hline 2,3 & 509.92 & 456.76 & 108.38 & 121.34 \\
\hline 3,0 & 508.41 & 471.00 & 108.07 & 121.03 \\
\hline 3,1 & 469.58 & 443.64 & 105.56 & 118.39 \\
\hline 3,2 & 501.47 & 468.80 & 108.46 & 118.97 \\
\hline 3,3 & 502.77 & 470.61 & 110.26 & 121.12 \\
\hline
\end{tabular}

Table 2- Absolute maximum moment and shear forces in a typical intermediate column

\begin{tabular}{|c|c|c|c|c|}
\hline $\mathrm{P}(\mathrm{x}, \mathrm{y})$ & $\begin{array}{l}\mathrm{Mx} \\
\mathrm{kN}-\mathrm{m}\end{array}$ & $\begin{array}{l}\text { My } \\
\text { kN-m }\end{array}$ & $\begin{array}{l}\mathrm{Vx} \\
\mathrm{kN} \\
\end{array}$ & $\begin{array}{l}\mathrm{Vy} \\
\mathrm{kN}\end{array}$ \\
\hline 0,0 & 220.34 & 195.06 & 49.54 & 67.89 \\
\hline 0,1 & 220.87 & 196.65 & 49.32 & 66.74 \\
\hline 0,2 & 491.51 & 453.97 & -108.94 & 128.76 \\
\hline 0,3 & 492.50 & 466.74 & 113.59 & 130.72 \\
\hline 1,0 & 496.50 & 452.10 & 108.11 & 130.27 \\
\hline 1,1 & 517.66 & 472.81 & 112.79 & 135.14 \\
\hline 1,2 & 518.25 & 470.97 & 111.10 & 135.78 \\
\hline
\end{tabular}




\begin{tabular}{|l|l|l|l|l|}
\hline 1,3 & 522.39 & 474.43 & 112.01 & 136.71 \\
\hline 2,0 & 522.02 & 473.72 & 111.83 & 136.61 \\
\hline 2,1 & 516.39 & 472.32 & 112.48 & 134.87 \\
\hline 2,2 & 524.57 & 477.67 & 112.60 & 137.28 \\
\hline 2,3 & 522.39 & 475.30 & 112.23 & 136.74 \\
\hline 3,0 & 498.88 & 446.93 & 108.65 & -92.85 \\
\hline 3,1 & 516.38 & 473.06 & 112.48 & 134.88 \\
\hline 3,2 & 522.06 & 476.17 & 112.19 & 136.75 \\
\hline 3,3 & 507.62 & 472.76 & 113.91 & 135.10 \\
\hline
\end{tabular}

Table 3- Absolute maximum moment and shear forces in a typical interior column

\begin{tabular}{|l|l|l|l|l|}
\hline & \multicolumn{2}{|l}{} & & \\
$\mathrm{P}(\mathrm{x}, \mathrm{y})$ & $\mathrm{kN}-\mathrm{m}$ & $\mathrm{My}$ & $\mathrm{Vx}$ & $\mathrm{Vy}$ \\
$\mathrm{kN}-\mathrm{m}$ & $\mathrm{kN}$ & $\mathrm{kN}$ \\
\hline 0,0 & -211.60 & 218.80 & 57.70 & 54.73 \\
\hline 0,1 & -206.59 & 220.15 & 57.42 & 69.45 \\
\hline 0,2 & -506.30 & 508.87 & 132.46 & 137.53 \\
\hline 0,3 & 501.17 & 499.32 & 125.91 & 139.67 \\
\hline 1,0 & -511.05 & 510.24 & 129.90 & 139.03 \\
\hline 1,1 & -532.65 & 532.06 & 135.12 & 144.37 \\
\hline 1,2 & -532.82 & 530.80 & 133.78 & 144.86 \\
\hline 1,3 & -536.42 & 535.79 & 135.10 & 145.69 \\
\hline 2,0 & -536.66 & 535.55 & 135.20 & 145.77 \\
\hline 2,1 & -531.36 & 529.88 & 134.25 & 144.07 \\
\hline 2,2 & -539.28 & 536.69 & 135.06 & -146.51 \\
\hline 2,3 & -536.42 & 535.16 & 134.83 & 145.71 \\
\hline 3,0 & -495.48 & 507.18 & 132.75 & 128.56 \\
\hline 3,1 & -531.35 & 529.07 & 133.75 & 144.08 \\
\hline 3,2 & -536.73 & 533.31 & 134.01 & 145.93 \\
\hline 3,3 & -496.06 & 510.69 & 137.83 & 126.29 \\
\hline & & & & \\
\hline
\end{tabular}

\subsection{Moment and Shear Forces variation along the}

\section{Height of a Flat Slab Building:}

In a 10 storey flat slab building, the moments and shear forces along the height of the building for a typical interior column for position $\mathrm{P}(3,3)$ are plotted and are shown in Fig. 10 and Fig. 11.

Absolute maximum moment for static loading occurs at the first storey, rapidly decreasing in the next storey, and then remaining almost constant. Absolute maximum moments under earthquake loading condition follow the same trend as that under static loading.

Absolute maximum shear forces have the same trend under static and seismic loads. There is a sudden rise in the shear forces in the bottom storey and top storey. In the remaining storeys the maximum shear is almost remaining constant.

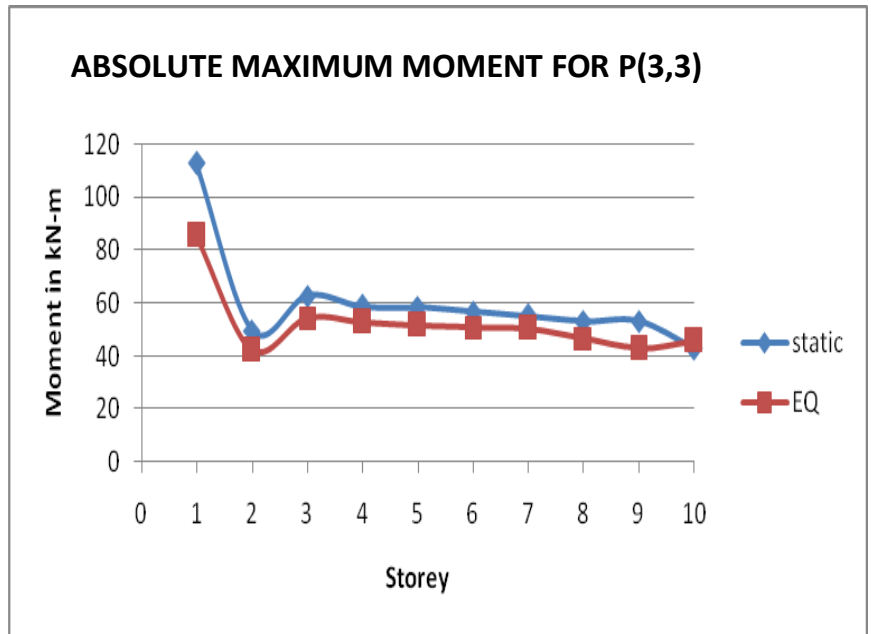

Fig.10 : Variation of moments along height of building for static and earthquake loads

\section{ABSOLUTE MAXIMUM SHEAR FORCE FOR P(3,3)}

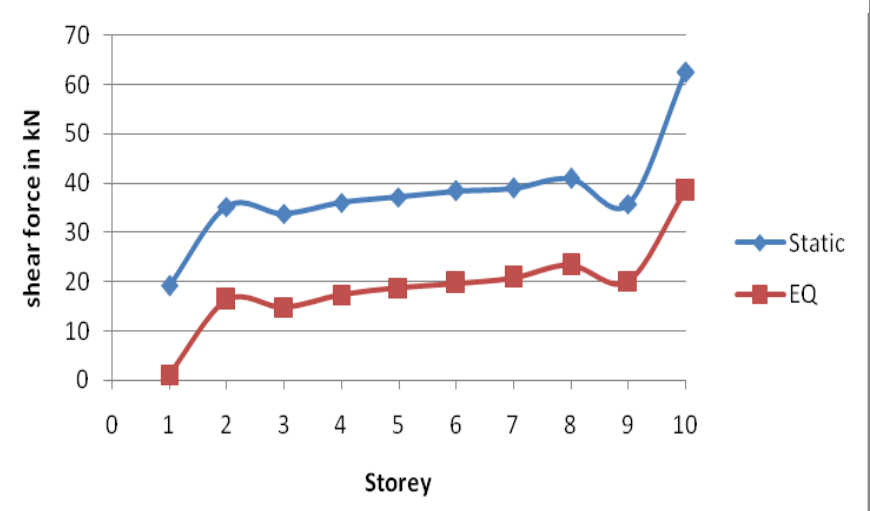

Fig.11 : Variation of Absolute shear forces along height of building for static and earthquake loads

\section{CONCLUSION}

Based on the studies conducted on a number of numerical models of flat slab structures in this work, the following conclusions could be drawn.

\section{General}

1. The flat slab structure is sensitive to the position of an interior column and attains criticality when that column is placed at maximum eccentricity (w.r.t its original position, which otherwise makes the grid rectangular), on ' $\mathrm{X}$ ' and/or ' $\mathrm{Y}$ ' axes.

2. Column strips in the direction opposite to the movement of the interior column under consideration (whose position $\mathrm{p}(\mathrm{x}, \mathrm{y})$ is chosen as a variable here) get de-linked with this column while new strips are formed linking this column with all the nearly column.

3. The absolute maximum shears and moments occurring in both the inner and outer peripheral column strips, when the interior column moves farthest $(\mathrm{P}(3,3))$ from its original position $(\mathrm{P}(0,0))$ 
4. Out of the three types of columns observed (corner, side, interior) interior columns which are farther from the $\mathrm{C} 3$ are becoming more critical for $\mathrm{P}(3,3)$ position under seismic load considerations.

5. . Results reveal that there is every need to consider the effect of non rectangularity column grids on the formation of column strips, moments and shears in column strips, the detailing of reinforcement in column strips and also the moments in the columns of such flat slab structures.

\section{REFERENCES}

[1]. J.P.Narayana, "Numerical studies on flat slab structures supported on non- rectangular grids", a dissertation submitted to Osmania University, Hyderabad, 2009

[2]. Frederick P. Wiesinger., “Design of Flat Plates with Irregular Column Layout”, ACI journal, Document Title no 70-12, February 1973

[3]. K.Bhaskaran, C.T.Morley, "Strength Assessment of Flat Slabs on Non-Rectangular Column Grid", www.concreteresearch.com, online paper, 2007

[4]. Ahmad J.Durani, T.Mau, AmrAhmed AbouHashis., "Earthquake Response of Flat Slab Buildings", Journal of Structural Engineering, Vol 120, No-3, March 1994, 947964

\section{BIOGRAPHIES}

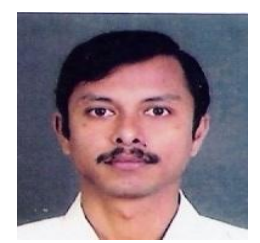

Jayaprakash Narayana. $\mathrm{S}$ is currently working as Assistant Professor in Civil Engineering department of Mahatma Gandhi Institute of Technology, Hyderabad. He has three years of filed exposure besides five years of teaching experience. He enthusiastically gains simultaneous exposure to the field problems of Civil Engineering.

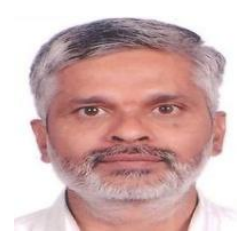

Sreenivas Sarma. P is currently the Head of Civil Engineering department at CBIT. He has 32 years of teaching experience with a simultaneous exposure to the practicing field of Civil Engineering. He has special expertise in retrofitting of structures with a special focus on seismic retrofitting 